\title{
Biofilm formation by Methicillin resistant Staphylococcus aureus and its relation to antibiotic resistance in Thi-qar province/Iraq
}

\author{
Saad A. Atiyah saad-abd@utq.edu.iq \\ Dept. Microbiology\College of MedicinelUniversity of Thi-Qar
}

\begin{abstract}
Methicillin resistant Staphylococcus aureus is one of the most dangerous pathogens in the community and the hospital environment for its high resistance to antibiotics and the production of a number of virulence agents such as toxins and biofilm. The study aims to determine the ability of local isolates to produce the biological membrane and its relationship to resistance to antibiotics. A cross sectional study include (37) isolates of methicillin-resistant $S$. aureus from the burn department at AlHussein Teaching Hospital in Thi Qar province/Iraq for the period April-October 2015, The capacity of bacteria to produced biofilm was done by micro plate technique and the antibiotic susceptibility test for vancomycin, amikacin, ciprofloxacin, norfloxacin, cefotaxime and amoxicillin-Claviolinate using the diffusion technique of antibiotic disks. The study showed that $64.9 \%$ of the MRSA isolates were able to form biofilm, while the isolates were fully resistant to the used beta-lactam antibiotics. But, the $94.6 \%$ of the isolates were sensitive to the vancomycin. There was no significant statistical relationship between the antibiotic resistance and the ability of bacteria to produce the biofilm except for the ciprofloxacin. The study showed that the local MRSA isolates have a high ability to produce the biological membrane and antibiotic resistance with the exception of the vancomycin with a relationship between the resistance to ciprofloxacin and the production of the biological membrane by bacteria. Therefore, the study recommends the use of vancomycin in medical sites to treat the infections caused by MRSA to prevent the spread and development of these resistant strains.
\end{abstract}

Keywards: Biofilm, Staphylococci, antibiotic resistance

\section{Introduction}

Staphylococcus aureus is a gram positive cocci may present as normal flora in skin and mucus membrane especially in the nose but it considered as an important medical pathogen associated with the different types of community and hospital acquired infections range from mild skin infections to severe infections such as toxic shock syndrome and pneumonia, 


\section{Email:utjmed@utq.edu.iq}

this bacterium able to produce several types of toxins and virulence factors that help in initiation and development of infections e.g. hemolysin and coagulase. In addition to this. S. aureus developed resistance rapidly to the different classes of antibiotics like $\beta$ lactams and aminoglycosides. ${ }^{(1,2,3)}$

Methicillin resistant Staphylococcus aureus (MRSA) was firstly reported in Europe in 1960s, ${ }^{(4,5,6)}$. Its became a significant pathogens causing a variety of nosocomial life-threatening infections such as ventilator-associated pneumonia, catheter related infections, sepsis, endocarditis and soft tissue infections that lead to increases in mortality and morbidity among hospitalized patients and increase the cost of treatment, the asymptomatically colonized healthcare workers are the major sources of MRSA in the hospital environment. There have been an increasing number of outbreaks of MRSA infections in hospitals reported from many countries. Today, the infections by MRSA isolates are reported in most communities not only in hospitals with high resistance to many antibiotics classes ${ }^{(1,5,6,7)}$.

The most important problem in treatment of MRSA is the development of multi-drug resistant (MDR) isolates in hospital and community acquired infections specially to many commonly used antibiotics and the ability of MRSA to develops resistance to vancomycin which is used to management of MRSA infections for decades are reported in many countries. So, the MDR isolates appearing lead increase difficulty in treatment, morbidity, mortality and increase requirement to screening the anti-biogram of MRSA in different medical settings and communities. Clinical infections are most common in patients in hospital intensive care units, nursing homes, and other chronic care facilities; however, MRSAs are emerging as an important community acquired pathogen as well. Although there are some reports on the prevalence of vancomycin resistant $S$. aureus (VRSA) and vancomycin intermediate $S$. aureus (VISA), most MRSA isolates are susceptible to vancomycin and teicoplanin; therefore resistance increase to these antibiotics results in the limitation of treatment options and also the requirement of a new class of antibiotics ${ }^{(7,8)}$.

The biofilm is complex sessile cells communities embedded in the polymers from exopolysaccharides matrix produced by themselves, it help bacteria to adhesion on environmental surfaces and host tissue to initiates infections. The adhesion of biofilm and its development provides an ideal environment for germs and overlap with each other to help in the exchange of genetic material and metabolites between them, Also, biofilm appear to be represents an important microbial survival mechanism used by bacteria to resist of the non-desired conditions like desiccation, antimicrobial agents etc ${ }^{(9)}$.

The researchers was recorded many MRSAare a biofilm formation bacteria in different medical settings which is increase the persistence of bacteria and 


\section{Email:utjmed@utq.edu.iq}

their ability to resistance of antibiotics and the action of immune system e.g. phagocytosis, some host factors aid in biofilm formation such as adhesive factors and capsules ${ }^{(10)}$.

The study aimed to determine the ability of local isolates of MRSA to form biofilm and its relation to antibiotics resistance.

\section{Methodology}

\section{Bacterial isolates}

A cross sectional study including (37) isolates of Methicillin resistant $S$. aureus were obtained from the patients with burn infections in Al-Hussein teaching hospital Thi qar province/Iraq in the period from April to October / 2015. the diagnosis of bacteria were done by using standard biochemical techniques.

\section{Antibiotic susceptibility test}

The test was achieved by disk diffusion technique with the following antibiotics vancomycin (VAN), amikacin (AK), ciprofloxacin (CIP), norfloxacin (NOR), cefotaxime (CTX), Co-amoxyclav (AMC) and methicillin (MET) discs provided by (BioanalyzeTurkey) ${ }^{(11)}$.

\section{Biofilm formation}

S. aureus isolates were inoculated in test tubes each of which containing (3) $\mathrm{ml}$ of trypticase soya broth (TSB) and incubated at a temperature of $25^{\circ} \mathrm{C}$ for 24 hours.

B .bacterial culture washed by TSB diluted 1: 3 three times using the centrifuge (3000 rpm).

C.The number of cells in each tube calculated by microscopic examination using Petroff-Hausser chamber for the concentration ranges between $\left(5 \times 10^{5}\right.$ $\left.1 \times 10^{6}\right) \mathrm{CFU} / \mathrm{ml}$.

D. A volume of $(200 \mu \mathrm{l})$ of culture from each isolate tube was add to rounded bottom microtiter plate then incubated at $25{ }^{\circ} \mathrm{C}$ for 24 hours, wells with TSB only was used as control.

E. The culture was removed from wells and washed three times by normal saline. the plates incubated at $60{ }^{\circ} \mathrm{C}$ for one hour, then the wells was stained by crystal violet for 5 minutes, the plate washed with running water to get rid the remnants of pigment, plates were incubated at a temperature $37^{\circ} \mathrm{C}$ for 30 minutes to dry.

F. The absorbency of formed biofilm was read by Microplate reader (Biotech-USA) at wavelength of 492 $\mathrm{nm}^{(12)}$.

\section{Statistics}

The statistical analysis was performed by using SPSS program (version 19). 


\section{Results}

Table (1) shown the isolates ability to form biofilm as the 24 isolates represents $(64.9 \%)$ have had the ability to produce the biofilm on plastic surfaces of micro titer plate.

Table (1): Biofilm formation by MRSA isolates.

\begin{tabular}{|l|l|l|}
\hline Biofilm formation & Frequency & Percent (\%) \\
\hline Positive & 24 & 64.9 \\
\hline Negative & 13 & 35.1 \\
\hline Total & 37 & 100 \\
\hline
\end{tabular}

The MRSA isolates were completely resistant (100\%) to $\beta$-lactam drugs in this study including cefotaxime and Co-amoxyclav, highly resistance was shown to ciprofloxacin and norfloxaacin in percent $(67.6 \%, 73 \%)$, respectively. Amikacin showed moderate activity against MRSA were (59.5\%) of isolates expressed resistance. While, vancomycin was the most active antibiotic used, 2 isolates represents $(5.4 \%)$ were resistant to VAN with high significant differences under $(\mathrm{P}<$ 0.001 ) in compared with other antibiotics as shown in table (2).

Table (2): Antibiotics Susceptibility pattern for MRSA isolates from burn infections.

\begin{tabular}{|l|l|l|l|l|}
\hline \multirow{2}{*}{ Antibiotics } & \multicolumn{2}{|l|}{ Susceptible } & Resistant \\
\cline { 2 - 5 } & No. & $\%$ & No. & $\%$ \\
\hline Vancomycin & 35 & 94.6 & 2 & 5.4 \\
\hline Amikacin & 15 & 40.5 & 22 & 59.5 \\
\hline Ciprofloxacin & 12 & 32.4 & 25 & 67.6 \\
\hline Norfloxacin & 10 & 27 & 27 & 73 \\
\hline Cefotaxime & 0.0 & 0.0 & 37 & 100 \\
\hline Co-amoxyclav & 0.0 & 0.0 & 37 & 100 \\
\hline
\end{tabular}


The results showed no significant correlation between biofilm production and resistance of bacteria to antibiotics (VAN,AK,NOR,CTX and AMC) under the $(\mathrm{P}<0.05)$. While, there were significant differences between sensitivity pattern of CIP and the capacity of MRSA to produced biofilm under the probability of less than 0.05 , as shown in Table (3).

Table (3): Relationship between antibiotic susceptibility and biofilm formation

\begin{tabular}{|l|l|l|l|l|}
\hline \multicolumn{2}{|c|}{ Biofilm antibiotic } & Positive & Negative & Total \\
\hline VAN & S* & 22 & 13 & 24 \\
\cline { 2 - 4 } & $\mathrm{R}^{* *}$ & 2 & 0.0 & 13 \\
\hline \multirow{2}{*}{ AK } & S & 9 & 6 & 15 \\
\hline CIP & R & 15 & 7 & 22 \\
\hline \multirow{2}{*}{ NOR } & S & 5 & 7 & 12 \\
\hline \multirow{2}{*}{ CTX } & R & 19 & 6 & 25 \\
\hline \multirow{2}{*}{ AMC } & S & 5 & 5 & 10 \\
\hline & R & 19 & 8 & 27 \\
\hline & S & 0.0 & 0.0 & 0.0 \\
\hline & R & 24 & 13 & 37 \\
\hline
\end{tabular}

*susceptible ** resist

\section{Discussion}

MRSA now represents an important health problem worldwide with increase incidence of these bacteria in different types of infections dramatically including community and hospital acquired MRSA infections which ranging from skin and soft tissue infections to serious sepsis and pneumonia $^{(13,14)}$.

MRSA isolates showed high resistance to antibiotics under study, especially beta-lactam drugs. This may be due to the increased transmission of resistance genes between these bacteria and other species found in the hospital environment. The increased use of antibiotics in the community and the hospital made these bacteria in great contact with antibiotics, While, vancomycin were the most effective antimicrobial agents against MRSA isolates which may be due to low rate of using of this antibiotic in the community or in medical sites. This study is consistent with a number of other studies that have shown that MRSA isolates are highly resistant to many antibiotics and highly sensitive to vancomycin. $(7,15)$

In this study, MRSA showed increase ability to biofilm production, and this is evidenced by a number of 


\section{Email:utjmed@utq.edu.iq}

studies as observed high capacity of these bacteria to produce biofilm in different environments, especially in the hospital, and this may be due to the ability of the bacteria to produce a number of adhesion factors which helps in the initiation of first step biofilm formation and the isolates of bacteria began to show high capacity to produce extra-cellular polysaccharides which are the main components of the biological membrane ${ }^{(16,17)}$. Ciprofloxacin is widely used in eradication of biofilm of many bacteria ${ }^{(18,19,20)}$, this resistance antibiotic showed significant correlation with biofilm formation may because the relation between genes that responsible for resistance and those that help in production of adhesive factors or polysaccharide production as where these genes may be located under the effects of the same regulatory gene.

The increase development of antibiotic resistance with increased ability to biofilm production, as demonstrated by the study, is a major problem especially in the hospital environment. Attached bacteria (sessile cells) to the membrane are inactive which increase resistance. The low metabolism of sessile cells in biofilm reduces the deadly effect of antibiotics. Many of these antibiotics are highly effective against high-metabolizing cells, and since free cells in this study have shown high resistance to most of the widely used antibiotics in community. Also, The biofilm acts as a diffusion barrier that prevents the antibiotic from reaching to embedded cells or reducing the concentration of the antibiotics in biofilm ${ }^{(9,21,22)}$. This has compounded problem by the development of chronic infections and increased mortality and morbidity rates. As it reduced the options for the use of antibiotics. So, the patients needs a high concentration of active anti-MRSA antibiotics to eliminate the bacteria in the membrane.

\section{Conclusion}

The study showed that the local isolates of MRSA have a high ability to produce the biological membrane and antibiotic resistance with the exception of the vancomycin with a relationship between the resistance to ciprofloxacin and the production of the biological membrane by bacteria.

\section{Recommendation}

the study recommends the use of vancomycin in medical sites to treat the infections caused by MRSA to prevent the spread and development of these resistant strains

\section{References}

1. Howden BP, Davies JK, Johnson PD, Stinear TP, Grayson ML. (2010). Reduced vancomycin susceptibility in Staphylococcus aureus, including vancomycinintermediate and heterogeneous vancomycin-intermediate strains: resistance mechanisms, laboratory detection, and clinical implications. Clin. Microbiol. Rev. 23(1):99-139.

2. Brooks GF, Butel, JS and Morse SA, (2004) . Jawetz, Melnick, \& 
Adelberg's Medical Microbiology, $23^{\text {rd }}$ Edition McGraw-Hill Companies .

3. Turlej A, Hryniewicz W, Empel J. (2011) Staphylococcal cassette chromosome mec (Sccmec) classification and typing methods: an overview. Pol. J Microbiol. 60(2):95103.

4. Chambers HF. (2011). The changing

of Staphylococcus epidemiology Infect. Dis. 7:178-82.

5. Cox RA, Conquest C, Mallaghan C, Marples RR. (1995). A major outbreak of methicillin resistant Staphylococcus aureus caused by a new phage type (EMRSA-16) J Hosp. Infect. 29:87-106.

6. Deurenberg RH, Stobberingh EE. (2009). The molecular evolution of hospital- and community-associated methicillin-resistant Staphylococcus aureus. Curr. Mol. Med. 9(2):100-15.

7. Saha B, Singh AK, Ghosh A. and et al. (2008). Identification and characterization of a vancomycinresistant Staphylococcus aureus isolated from Kolkata (South Asia) J Med. Microbial. 57:72-9.

8. Hiramatsu K, Hanaki H, Ino T, et al. (1997). Methicillin-resistant Staphylococcus aureus clinical strain with reduced vancomycin susceptibility. J Antimicrob. Chemother. 40:135.

9. Costerton JW, Stewart PS, Greenberg EP. (1999). Bacterial biofilms: a common cause of persistent infections. Science. 21(284):1318-22.

10. Eiichi A, Koichi M, Ritsuko M, et al. (2004). Biofilm formation among methicillin-resistant Staphylococcus aureus isolates from patients with urinary tract infection. Acta Med. Okayama 58 (4): 207-214.

11. Forbes BA, Daniel FS and Alice SW, (2007). Bailey and Scott's diagnostic microbiology. 12th. ed. ,Mosby Elsevier company, USA

12. Christensen GD, Simpson WA, Younger JJ, et al. (1985). Adherence of coagulase-negative staphylococci to plastic tissue culture plates: a quantitative model for the adherence of staphylococci to medical devices. J Clin. Microbiol. 22:996-1006.

13. Frazee BW, Lynn J , Charlebois ED, et al (2005). High prevalence of methicillin resistant Staphylococcus aureus in emergency department skin and soft tissue infections . Ann. Emerg. Med. 45 : 311 -20 .

14. Moran GJ , Amii RN , Abrahamian FM , et al. (2005). Methicillin-resistant Staphylococcus aureus in community-acquired skin infections . Emerg. Infect. Dis. 11 : $928-30$.

15. Singh R, Ray P, Das A, Sharm a M. (2010). Penetration of antibiotics through Staphylococcus aureus and Staphylococcus epidermidis biofil ms. J Antimicrob. Chemother. 65:1955 - 1958; 16. Mack D, Fischer W, Krokotsc h A, et al. (1996). The intercellular adhesin involved in biofilm accumulation of Staphylococcus epidermidis is a linear beta-1,6-linked glucosaminoglycan: purification and structural analysis. J Bacteriol. 178:175- 183

17. Croes, S, Deurenberg, RH, Boumans, ML, et al., (2009). Staphylococcus aureus biofilm formation at the physiologic glucose 


\section{Email:utjmed@utq.edu.iq}

concentration depends on the $S$. aureus lineage. BMC Microbiology.

18. Smith, SM, Eng, R and TecsonTumang, F. (1989). Ciprofloxacin therapy for methicillin-resistant Staphylococcus aureus infections or colonizations. Antimicrob. Agents Chemother. 33(2): 181-184.

19. Morvarid, S, Ahya, AA, Fereshteh, S, et al., (2014). Eradication of Pseudomonas aeruginosa biofilms using the combination of $n$-butanolic Cyclamen coum extract and ciprofloxacin. Jundishapur J Microbiol. 7(2).
20. Vivek V. Harjai $\mathrm{K}$ and Chhibber S. (2009). Restricting ciprofloxacin-induced resistant variant formation in biofilm of Klebsiella pneumoniae B5055 by complementary bacteriophage treatment. J Antimicrob. Chemother.64: 1212- 1218.

21. Lewis K. (2010). Persister cells. Annu. Rev. Microbiol. 64:357 372.

22. $\mathrm{Xu} \mathrm{KD}, \mathrm{McFeters} \mathrm{GA}$ and Stewart PS. (2000). Biofilm resistance to antimicrobial agents. Microbiology 146:547 - 549; 


\title{
إنتاج الفشاء الحيوي بواسطة المكورات العنقودية الذهبية المقاومة للمضاد مشيلين و علاقته

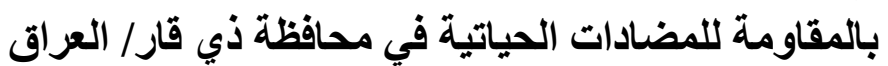

\author{
سعد عبد العزيز عطية
}

\section{الخلاصة}

تعد المكورات العنقودية الذهبية المقاومة للمضاد مثشيلين من أكثر الممرضات خطورة في المجتمع و بيئة

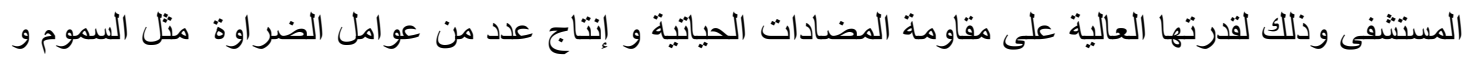

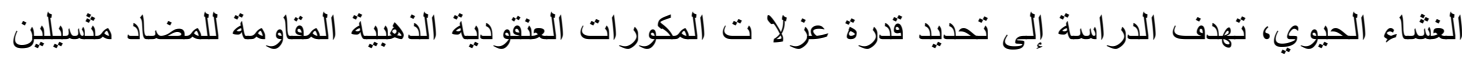

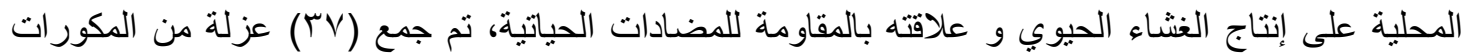

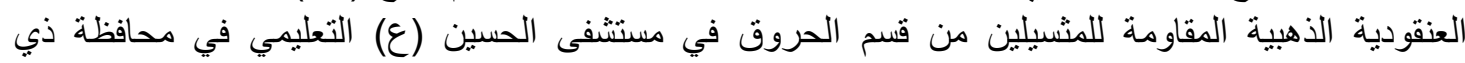

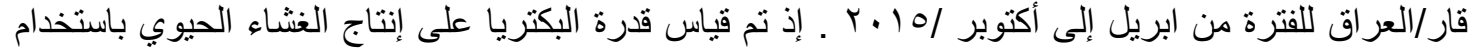

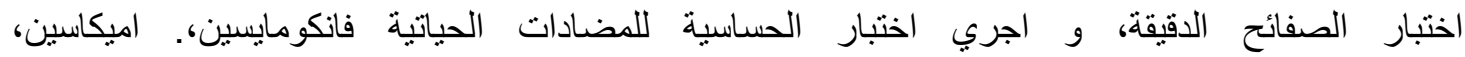

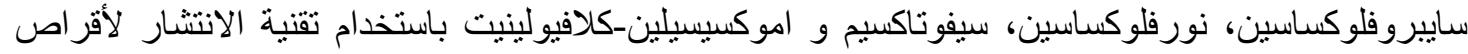

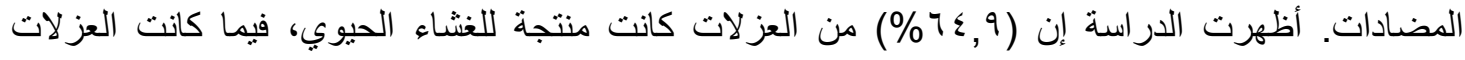

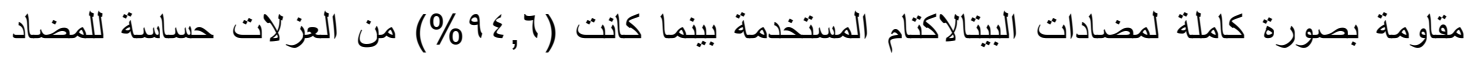

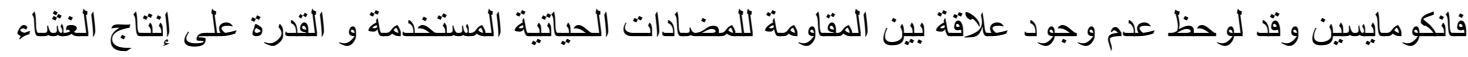

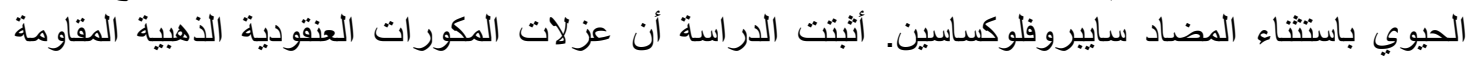

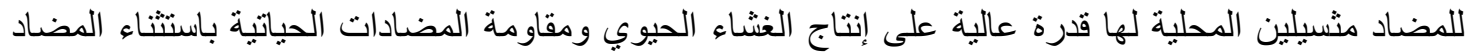

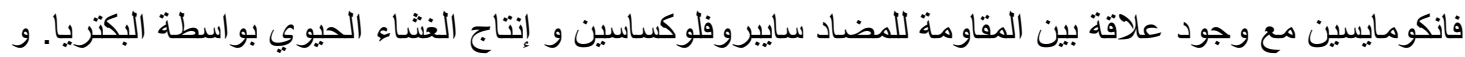

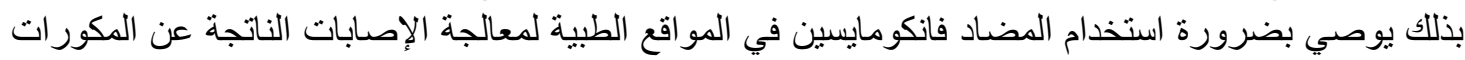

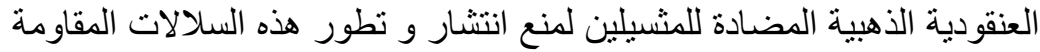

